\title{
EXPERIMENTAL STUDY ON THE PERFORMANCE AND EMISSION CHARACTERISTICS OF PPCCI ENGINE FUELED WITH BIODIESEL/DIESEL BLENDS
}

\author{
E. A. El Shenawy, Medhat Elkelawy, Hagar Alm-Eldin Bastawissi, Mahmoud. M. Shams \\ Department of Mechanical Power Engineering, Tanta University, Tanta, Egypt
}

\begin{abstract}
This paper studies the combustion, performance and emission characteristics for one of the advanced engines called partially premixed charge compression ignition engine by using blends of diesel and biodiesel fuel. The partially premixed charge compression ignition engine is one of the homogenous charge compression ignition engines which aim to reduce the temperature of the ignition, improve the performance of the engine and reduce the emitting emissions. The experiment is performed in a four-stroke constant speed and air cooled diesel engine which is modified by using intake manifold to work as partially premixed charge compression ignition engine. From the experiment it was observed reduction in the emissions of engine like NOx emission by over $40 \%$ of values in particles per minute compared with the conventional diesel engine and by over $60 \%$ of values in particles per minute using $30 \%$ blend of biodiesel also increasing in the brake thermal efficiency in the two cases of using diesel fuel by over $10 \%$ or using $30 \%$ blend of biodiesel and diesel by over $30 \%$.

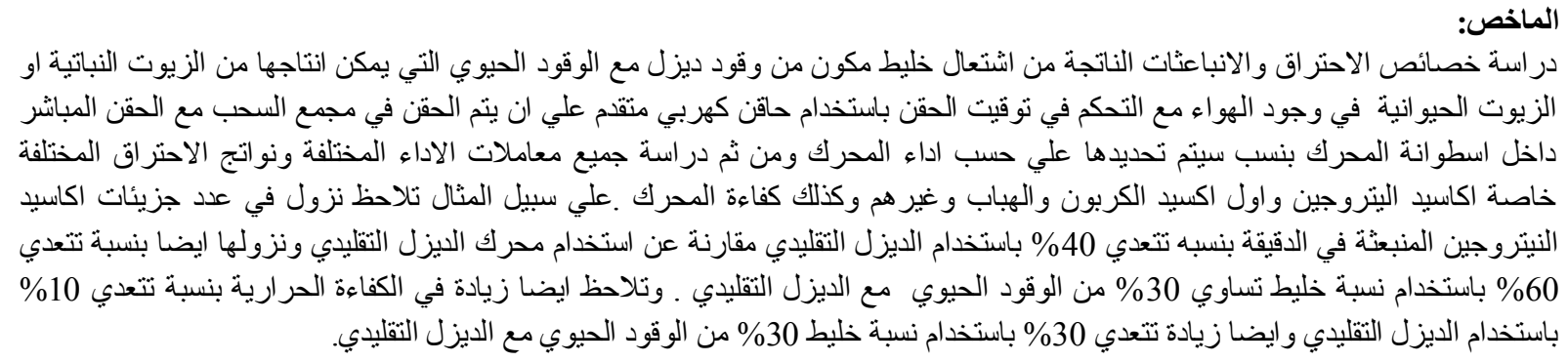

Keywords : Diesel engine, diesel engine, emissions, PPCCI combustion, premixed ratio, waste cooked oil.

Symbols and abbreviations

\begin{tabular}{|l|l|}
\hline $\mathrm{A}=$ the area of the orifice in $\mathrm{m}^{2}$ & $m:$ is the mass of air through the orifice in $\mathrm{kg} / \mathrm{sec}$ \\
\hline BTE: brake thermal efficiency & $m^{\circ} 1:$ mass fuel consumption crossing the main injector \\
\hline BSFC: brake specific fuel consumption & $m^{\circ} 2:$ mass fuel consumption by the intake manifold \\
\hline BSEC: brake specific energy consumption & NOx: nitrogen oxides \\
\hline BTDC: before top dead center & PPCCI: partially premixed charge compression ignition \\
\hline CI: compression ignition & $\Delta \mathrm{P}=$ is the difference in pressure as measured in cm of water. \\
\hline CO: carbon monoxide & PR: premixed ratio \\
\hline $\begin{array}{l}\text { Cd= coefficient of the discharge of the orifice } \\
\text { and equal to } 0.6 .\end{array}$ & UHC: unburned hydrocarbon \\
\hline DME: dimethyl ether & $\rho \mathrm{a}=$ the density of air in $\mathrm{kg} / \mathrm{sec}$. \\
\hline DI: direct injection & $\rho \mathrm{w}=$ is the density of water in $\mathrm{kg} / \mathrm{sec}$. \\
\hline EGR: exhaust gas recirculation & $v^{\circ}:$ is the discharge of air from the orifice in $\mathrm{m}^{3}$ per second \\
\hline $\begin{array}{l}\text { HCCI: homogenous charge compression } \\
\text { ignition }\end{array}$ & \\
\hline
\end{tabular}




\section{Introduction}

Conventional diesel engine like compression ignition (CI) engine have a lot of merits such as the high brake thermal efficiency, the high output power, low fuel consumption and high reliability compared with the gasoline engines. However, diesel engines have demerits like high combustion temperature and high percentages of emissions so the direction of thinking about developing advanced techniques of diesel engines and alternative cleaner fuels become very important to get high performance of combustion and low emitted emissions.

The main type of the advanced diesel engines is the homogenous charge compression ignition (HCCI) engine which uses lean homogenous air-fuel mixture in the intake manifold and compressing the charge by the piston of the engine which causes the auto ignition for the mixture. The combustion by the HCCI engine is far from the unburned hydrocarbon (HC), monoxide carbon ( $\mathrm{CO}$ ) and monoxide nitrogen (NO) are the main advantages beside the high thermal efficiency and low temperature combustion [1].

To control the combustion with HCCI engine the operator must be take care about group of challenges such as the properties of the used fuel, the degree of homogeneity of fuel with air, the compression ratio, the intake temperature of the fuel Stanglmaier and Roberts [2], [3-5].

The methods of controlling the combustion in HCCI engine are a lot of methods but based on two strategies the first is increasing the mixture homogeneity and the second strategy is the timetemperature strategy [2, 6-8].

There are four strategies for mixture preparation classified into the external mixture formation which called also port fuel injection (PFI) strategy this is simple strategy for getting well mixture for the fuel and air but the used fuel must be have high degree of volatility like alcohol and need a preheating technique for low volatility fuels like diesel fuel to avoid the wall wetting into the cylinder[6], The second strategy for preparation the homogenous mixture is in cylinder mixture preparation which includes the early direct injection and the late direct injection. In the early direct injection the mixture is injected at the compression stroke which have a long delay ignition period so the mixing process is good but produce NOx and unburned hydrocarbon (UHC) because of the impingement of the fuel with the wall of the cylinder, the second type of in cylinder mixture preparation is the late direct injection which is retarded injection into the cylinder after the top dead center (TDC).

By using external mixture method for getting ideal mixture preparation by using a fuel vaporizer and $30 \%$ EGR in a single cylinder diesel engine without any modification, the experiments done without EGR and with $10 \%, 20 \%$ and $30 \%$ EGR, the results were compared with the conventional diesel engine and generally there were reduction in all emissions[6]. Homogenous mixture of petrol and air by using intake manifold and the experiments were performed at different speed it is observed That engine could operate smoothly at lean mixture of petrol and air with reduction in the NOx and smoke opacity emissions by $78 \%$ by the HCCI combustion compared with the conventional combustion[9]. It was observed that by using a multiple injection timing strategy with a dwell time between the two injections using the combustion performance was improved by using pure biodiesel as a fuel than using the diesel fuel and it is observed also reduction in the percentage of NOx emission up to $34 \%$ by pure biodiesel and multi injection timing[10].

By using HCCI combustion fuelled by biodiesel using port fuel injection with fuel vaporizer at 0 , $15 \%$, and $30 \%$ EGR and it is observed more stability for the combustion with biodiesel than diesel fuel and also decreasing in the $\mathrm{NOx}$ emissions[11]. Also there is an experimental and simulation analysis for late injection type of HCCI combustion with diesel and biodiesel by using high swirl ratio and EGR and it was observed high injection delay period which caused reduction in the NOx percentage and the smoke opacity[12].other investigation for HCCI combustion by using two cylinder engine one of them work as HCCI mode by using external mixture preparation include vaporizer and electronic control system and the other cylinder work at the conventional mode, using different EGR at $0 \%$ and $15 \%$ the combustion was improved compared by the conventional combustion such as reduction in NOx and $\mathrm{CO}$ to $80 \%$ and $50 \%$ 
respectively but the $\mathrm{HC}$ and $\mathrm{CO}$ are high compared by the conventional combustion [13].

Partially premixed charge compression ignition (PPCCI) engine is a compromise case between the conventional combustion and the homogenous charge compression ignition (HCCI) combustion which in this technique the most of the mixture is injected in the intake manifold and a small quantity of the mixture is direct injected by the main conventional injector. It is observed that all researches done at this point reduction in the temperature of the combustion and therefore reduction in emissions emitted from the combustion like NOx and the smoke also increasing in the brake thermal efficiency.

There was an investigation about partially premixed charge compression ignition (PPCCI) combustion and the emission by using dimethyl ether (DME) fuel and it is observed wide range of loads compared with the (HCCI) combustion also lower percentage of the unburned hydrocarbon (HC) and monoxide carbon (CO) and decreasing in the monoxide nitrogen (NOx) at most of the loads with high amounts of (NOx) at the high loads[14] . Also by using mixture of gasoline and ethanol as a fuel injected by the intake manifold and diesel fuel was direct injected into the cylinder it is observed reduction in the smoke, unburned hydrocarbon (HC) and (CO) emissions but the (NOx) emission was high at the injection timing of $25^{\circ}$ BTDC [15]. By using EGR in partially premixed charge compression ignition (PPCCI) combustion also using gasoline- diesel and n-heptane as a fuel with using EGR and it was observed reduction in soot and NOx emissions by increasing the premixed ratio at limited range of operation[16]. The effects of different compression ratio by using different heads of piston on the partially premixed charge compression ignition (PPCCI) combustion were studied by methanol-diesel blends using four stroke, air cooled single cylinder diesel engine. It is observed the brake thermal efficiency increases with $2 \%$ at 19.5 compression ratio using methanoldiesel blends than pure diesel only and reduction in the NOx by $56 \%$ but the (CO) and (UHC) were increased by $10 \%$ so the overall results of the 19.5 compression ratio was suitable for the (PPCCI) combustion and have low emissions[17]. By using $20 \%$ premixed ratio the combustion, performance and the emissions of (PPCCI) combustion were studied using ethanol and (90\% of gasoline and $10 \%$ of ethanol by volume) and diesel fuel direct injected in the combustion chamber by four stroke diesel engine from no load to the full load. It was observed reduction in smoke emissions by $70 \%$ by using the premixed gasoline and ethanol fuel compared to the diesel only also observed reduction in the oxide of nitrogen to $30 \%$ using the premixed gasoline and ethanol and finally increasing in the brake thermal efficiency by $20 \%$ compared to the diesel only combustion[18].

Due to the depletion, the rising prices and the produced emissions of the conventional fuels like diesel and gasoline fuel which have negative effects on the environment such as acid rains and the change in the climate. The direction for the alternative fuels becomes necessary to avoid the environmental degradation. From these alternative fuels are alcohols, natural gas, liquefied petroleum gas (LPG), dimethyl ether (DME) and biodiesel. Biodiesel is one of the alternative fuel which has a lot of resources like the edible vegetable oil which includes (rapeseed, soybean, peanut and sunflower), the non-edible vegetable oil which includes (jatropha, karanja), recycled cooking oils and animal fats like fish or chicken oils[19]. Biodiesel can be produced by four ways of production the first way is the pyrolysis which is a thermal decomposition for the biodiesel resource and convert the long chain alkyl esters to free fatty acids like alkanes, alkenes $[20,21]$. The second way for production is dilution with diesel fuel which uses a vegetable oils mixing with diesel fuel because the high viscosity of the vegetable oil without any chemical process[22]. The third way is the micro emulsion which used for solving the problem of high viscosity of the vegetable oils by using micro emulsion with immiscible liquid like methanol[22]. The fourth way is transestrification which is a chemical reaction which converts the triglyceride oil with alcohol such as methanol or ethanol using a catalyst such as $\mathrm{KOH}$ or $\mathrm{NaOH}$ to form free fatty acid of methyl or ethyl ester and glycerol and then purified and washed[22]. The biodiesel properties compared with diesel fuel properties are necessary for making blends used as a fuel and from the standard data of the two fuels it is observed that the biodiesel has higher density than diesel fuel, higher flash point, higher modulus of elasticity, higher cetane number so the ignition delay period is shorter for the biodiesel than diesel fuel, lower heating value due to the high percentage of 
oxygen which need high volume of biodiesel to get the same power comparing with diesel fuel, high viscosity which lead to poor atomization for the fuel[23]. Most of researches reported that the performance characteristics of the compression ignition diesel engines increased by using blends of diesel and biodiesel compared with $100 \%$ diesel fuel [24]. The objective of the recent research is to enhance the combustion process and reduce the emitting emissions by using partially premixed charge compression ignition (PPCCI) engine at different premixed ratio $20 \%, 25 \%$ and $30 \%$ and using blends of waste cooked oil biodiesel with diesel fuel.

\section{The experimental setup and procedure}

To investigate the performance and combustion characteristics using (PPCCI) engine fuelled with diesel and biodiesel blends. The experiments were performed on 4-stoke, single cylinder diesel engine Modified into (PPCCI) engine by using intake manifold for preparing the mixture of air and fuel before injection as shown in Figure 1. The intake manifold contains an electronic injector and fuel vaporizer for vaporizing the intake fuel which has low volatility. By using air box which have nozzles and orifices also inclined manometer for measuring air consumption by using the relations in appendix (A). The injection timing was controlled by control system which consists of crank angle encoder which used to monitor the rotary motion of the crank shaft of the diesel engine, motor driver, data acquisition system and software interface for entering the required angles of injection.

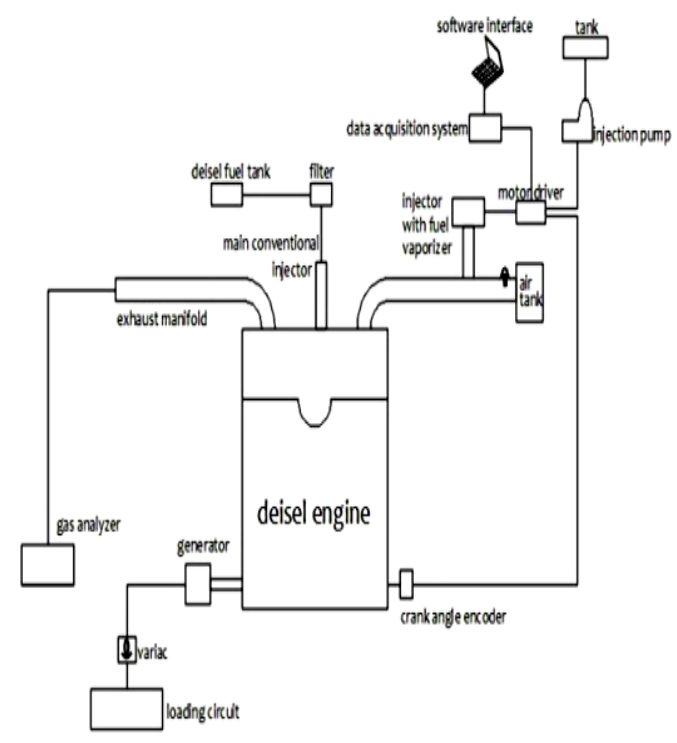

Figure1. Schematic layout of experimental setup

The real experimental setup is shown in Figure 2. Firstly the diesel engine has specifications which are given in Table 1. Run at the conventional mode for warming and preventing the cold start for the (PPCCI) combustion, during the operation at the conventional mode the performance and emissions were taken by using gas and smoke analyzer (HPC 500) after 39 seconds for warming after putting the probe at the exhaust and by using the monitor the emissions can be taken but the smoke opacity can be taken visually by using filter put at the behind of the analyzer which has resolution and range are given in Table 2. And the uncertainties of the measured parameters are given in Table 3. At no load and different loads by using the loading circuit which include groups of lamps, voltage indicators, ampere indicator and variac which controls the output power of the generator also the fuel consumption which suction by the main conventional injector must be measured by using burette at specified time and the consumption fuel injected by the electronic injector can be calculated by using weight scale at the bottom of the tank at specified time by using the relations in appendix (A). Then the combustion was switched into the (PPCCI) mode by using the intake manifold injection system with the main injector of the diesel engine at three premixed ratio are $20 \%, 25 \%, 30 \%$. During the three ratios the results of the performance and emissions were taken at no load and different loads. 


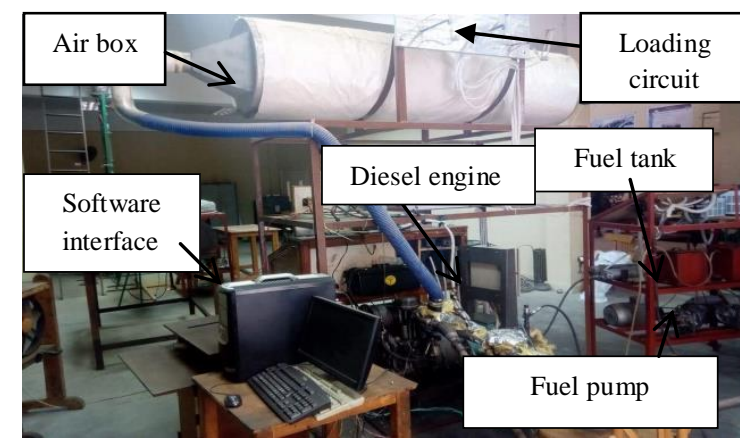

Figure2. Engine test rig

Table 1: Specifications of the used engine

\begin{tabular}{|c|c|}
\hline Specification data & Deutz FL 511/W \\
\hline No. of cylinder & 1 \\
\hline Bore & $100 \mathrm{~mm}$ \\
\hline Stroke & $105 \mathrm{~mm}$ \\
\hline Displacement & $825 \mathrm{c.c}$ \\
\hline Compression ratio & 17 \\
\hline Power & $7.7 \mathrm{hp}=5.7 \mathrm{kw}$ \\
\hline Cooling type & Air cooling \\
\hline Direction of rotation & Counter-clockwise \\
\hline Weight & 116 \\
\hline Lubrication system & Forced circulation \\
\hline Piston crown clearance & $1-1.2 \mathrm{~mm}$ \\
\hline Inlet valve opens & $32^{0}$ before TDC \\
\hline Inlet valve closes & $59^{0}$ after BDC \\
\hline Exhaust valve opens & $71^{\circ}$ before BDC \\
\hline Exhaust valve closes & $32^{0}$ after TDC \\
\hline Injection release pressure & 115 bar \\
\hline Lubrication system & Forced circulation \\
\hline Oil capacity & 2.4 liter \\
\hline Piston crown clearance & $1-1.2 \mathrm{~mm}$ \\
\hline
\end{tabular}

Table 2: Specifications of the gas analyzer

\begin{tabular}{|c|c|c|}
\hline Pollutant & Resolution & Range \\
\hline CO & $0.01 \times^{-2}($ vol $\%)$ & 0 to $10 \times 10^{-2}($ vol $\%)$ \\
\hline HC & $1 \times 10^{-} 6(\mathrm{PPM})$ & 0 to 10000 \\
\hline NOx & $1 \times 10^{-} 6(\mathrm{PPM})$ & 0 to5000 \\
\hline
\end{tabular}

Table 3: Uncertainties of the measured parameters

\begin{tabular}{|c|c|}
\hline Parameter & Percentage of the uncertainty \\
\hline CO & $\pm 0.03 \times 10^{-2}(\%)$ \\
\hline HC & $\pm 10 \times 10^{-} 6(\mathrm{PPM})$ \\
\hline NOx & $\pm 25 \times 10^{-} 6(\mathrm{PPM})$ \\
\hline Mass fuel consumption & $\pm 1.66 \%$ \\
\hline Brake thermal efficiency & $\pm 1.68 \%$ \\
\hline
\end{tabular}


Then the previous experiment was repeated by using blend of $30 \%$ biodiesel and $70 \%$ diesel which the used biodiesel was produced practically in the laboratory of Tanta University from waste cooked oil by transestrification process as shown in Figure 3 which mainly based on three stages as shown in Figure 4. The first stage of the transestrification process is the reaction stage which is mixing the waste cooked oil with methanol at $65^{\circ} \mathrm{c}$ about an hour by using a catalyst which is NAoH. The second stage is the separation to separate the methyl ester from the glycerol. The third stage is the washing stage for the produced methyl ester by using water at $100{ }^{\circ} \mathrm{c}$ and motor for shaking the mixture about an hour then the produced biodiesel separate from the water by opening the bottom valve of the tank and by blending $30 \%$ of the produced biodiesel with $70 \%$ of diesel which have properties shown in Table 4.[25]. The blend used for combustion the diesel engine at the

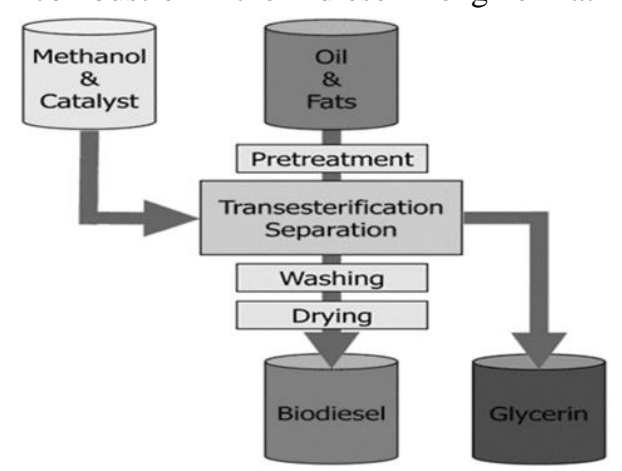

Figure4.Biodiesel production by the transestrification of triglyceride [26]. conventional mode and noting the results of the performance and the emissions at no load and different loads then by switching the combustion to (PPCCI) mode at the previous three premixed ratios $20 \%, 25 \%, 30 \%$ with noting the performance and emissions characteristics.

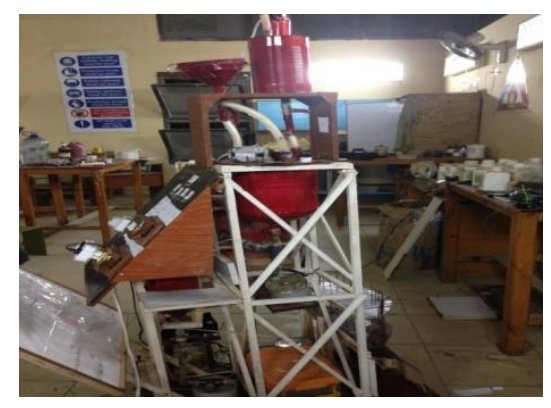

Figure 3 biodiesel production process

Table 4: Properties of diesel and biodiesel fuel

\begin{tabular}{|c|c|c|}
\hline Specification & Diesel & Biodiesel \\
\hline Standard & D 975 & D 6751 \\
\hline Density $\left(\mathrm{kg} / \mathrm{m}^{3}\right)$ & 830 & 875 \\
\hline Cetane number & 51 & 46 \\
\hline Kinematic viscosity & 1.3 & 120 \\
\hline Flash point $\left({ }^{0} \mathrm{c}\right)$ & 55 & 0.88 \\
\hline Specific gravity & 0.85 & 273 \\
\hline Auto ignition temperature $\left({ }^{0} \mathrm{c}\right)$ & 263 & 292 \\
\hline Molecular weight & 200 & $270-285$ \\
\hline Cloud point $(\mathrm{K})$ & $258-278$ & 0.05 \\
\hline Oxygen $(\mathrm{wt} . \%)$ & 0 & Fatty acid methyl esters \\
\hline Water $($ vol. $\%)$ & 0.05 & 39000 \\
\hline Composition & Hydrocarbons & \\
\hline Calorific value(MJ/KG) & 42000 & \\
\hline
\end{tabular}




\section{Result and discussion}

In this research the performance characteristics such as brake specific fuel consumption and the brake thermal efficiency were studied with respect to the engine load also the emissions characteristics such as carbon monoxide, unburned hydrocarbon, the oxides of nitrogen and the smoke emission with respect to the engine load also by using 100\% diesel fuel in the first case and at the second case using $30 \%$ biodiesel with $70 \%$ diesel at the conventional combustion and at three percentages of premixed ratios are PR $1=20 \%, \mathrm{PR} 2=25 \%$ and PR3 $=30 \%$ respectively. The measurements were conditioned by smooth performance of the engine and the measurements were stopped if there were vibration or knocking.

\subsection{Performance characteristics}

\subsubsection{Brake specific fuel consumption}

The variation of brake specific fuel consumption with engine load is shown in Figures 5A and 5B for the conventional combustion and (PPCCI) combustion at $20 \%, 25 \%$ and $30 \%$ premixed ratios respectively. the results showed that the brake specific fuel consumption decreases with increasing the engine load and its minimum value at the maximum load at each case of combustion and It is observed also that at any engine load the brake specific fuel consumption has the maximum value at the conventional combustion and the minimum value at (PPCCI) combustion with $30 \%$ premixed ratio. By comparison between the two graphs it is observed that the brake specific fuel consumption by using 30\% blend of biodiesel and diesel is smaller than the brake specific fuel consumption using diesel fuel at the same engine load, combustion and the same premixed ratio.

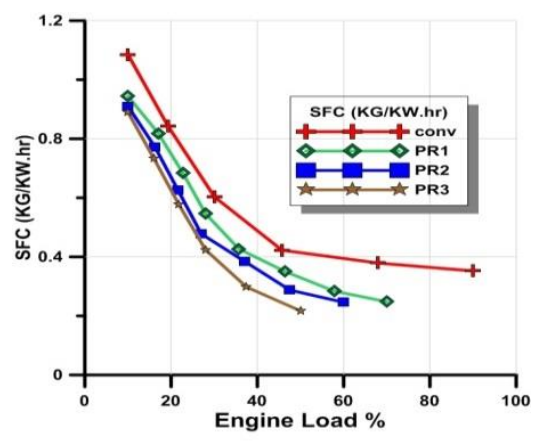

Figure 5A.Variation of brake specific fuel consumption with engine load using diesel fuel

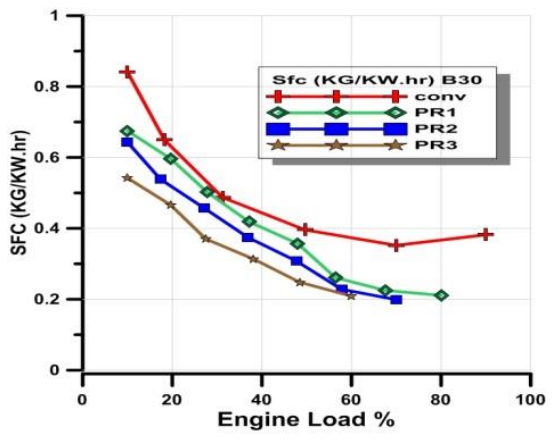

Figure 5B.Variation of brake specific fuel consumption with engine load using $30 \%$ blend of biodiesel and diesel.

The calculation of air to fuel ratio it is observed that air to fuel ratio were increased from range 36.4 at the conventional combustion mode of the diesel engine with diesel fuel to range 40.4 at (PPCCI) combustion mode with diesel fuel, at premixed $20 \%$ the air to fuel ratio was increased from range 44.62 with diesel fuel to 51.15 at $30 \%$ blend of biodiesel and diesel fuel, at premixed ratio $25 \%$ the air to fuel ratio was increased from range 49.123 with diesel fuel to 56.1 with $30 \%$ blend of biodiesel and diesel fuel and finally at premixed ratio $30 \%$ the air to fuel ratio was increased from range 60.5 with diesel fuel to 65.16 with $30 \%$ blend of biodiesel and diesel fuel.

So by using partially premixed charge compression ignition (PPCCI) combustion with ascending premixed ratio using blends of biodiesel and diesel as a fuel the brake specific fuel consumption will reduce with increasing the engine load but the air to fuel ratio will increase gradually.

\subsubsection{Brake thermal efficiency}

The variation of brake thermal efficiency with engine load is shown in Figures 6A and $\mathbf{6 B}$ for the conventional combustion and (PPCCI) combustion at $20 \%, 25 \%$ and $30 \%$ premixed ratios respectively, by using diesel fuel as shown in Figure 6A and using $30 \%$ blend of waste cooked oil biodiesel with diesel fuel at Figure 6B. It is observed from the two graphs that the brake thermal efficiency increases with increasing the engine load and its maximum value at the maximum load at each case of combustion, It is observed also that at any engine load the brake thermal efficiency has the minimum value at the conventional combustion and the 
maximum value at (PPCCI) combustion with 30\% premixed ratio. By comparison between the two graphs it is observed that the brake thermal efficiency by using $30 \%$ blend of waste cooked oil biodiesel and diesel is larger than the brake thermal efficiency using diesel fuel at the same engine load, combustion and the same premixed ratio because the specific fuel consumption using $30 \%$ blend of waste cooked oil biodiesel and diesel fuel is smaller the specific fuel consumption by diesel fuel only. So by (PPCCI) combustion with ascending premixed ratio with blends of biodiesel and biodiesel as a fuel the brake thermal efficiency will increase according to the engine load.

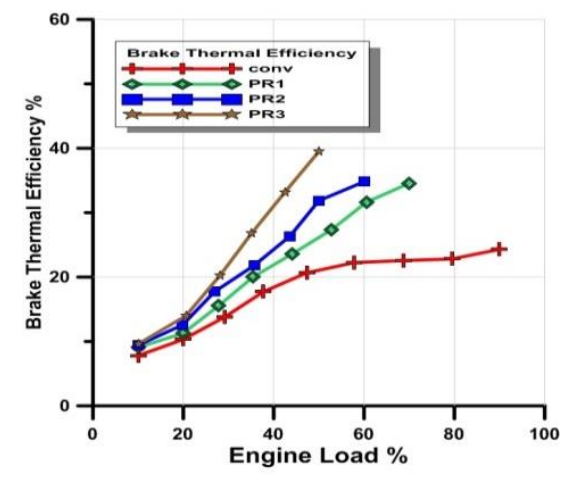

Figure 6A.Variation of brake thermal efficiency with engine load using diesel fuel.

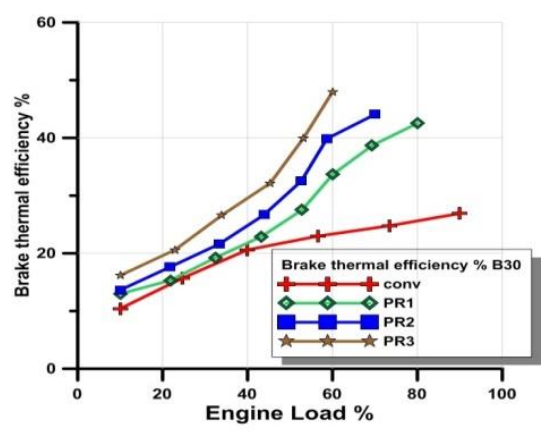

Figure 6B.Variation of brake thermal efficiency with engine load using $30 \%$ blend of biodiesel and diesel.

\subsection{Emissions characteristics}

\subsubsection{Carbon monoxide emissions}

The variation of carbon monoxide emissions with engine load is shown in Figures 7A and 7B for the conventional combustion and (PPCCI) combustion at $20 \%, 25 \%$ and $30 \%$ premixed ratios respectively, by using diesel fuel as shown in Figure 7A and using $30 \%$ blend of waste cooked oil biodiesel with diesel fuel at Figure 7B. It is observed from the two graphs that the carbon monoxide emissions decreases with increasing the engine load and its minimum value at the maximum load at each case of combustion, It is observed also that at any engine load the carbon monoxide emissions has the high percentages at the conventional combustion compared with the (PPCCI) combustion at $20 \%$, $25 \%$ and $30 \%$ premixed ratio which have low percentages of carbon monoxide emissions. By comparison between the two graphs it is observed that the percentages of carbon monoxide emissions by using $30 \%$ blend of waste cooked oil biodiesel and diesel is smaller than the percentages of carbon monoxide emissions using diesel fuel only at the same engine load, combustion and the same premixed ratio. So by using partially premixed charge compression ignition (PPCCI) combustion with ascending premixed ratio with blends of biodiesel and biodiesel as a fuel the carbon monoxide emissions percentages will reduce also it will reduce according to the engine load.

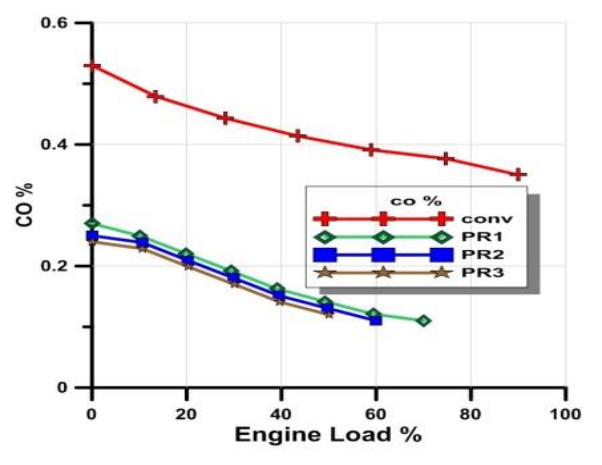

Figure 7A.Variation of carbon monoxide percentage with engine load using diesel fuel.

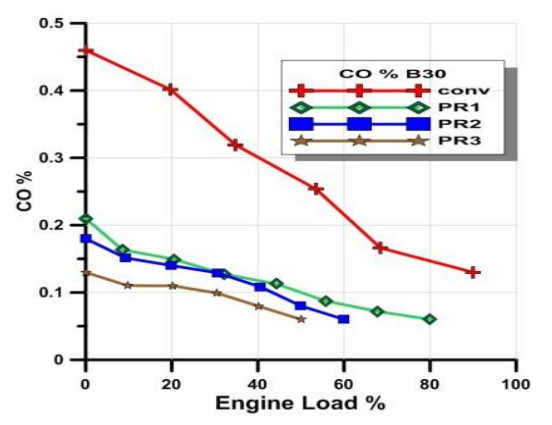

Figure 7B.Variation of carbon monoxide percentage with engine load using 30\% blend of biodiesel and diesel. 


\subsubsection{Nitrogen oxides emissions}

Figures $\mathbf{8 A}$ and $\mathbf{8 B}$ show the nitrogen oxides emissions with engine load for the conventional combustion and (PPCCI) combustion at 20\%, 25\% and $30 \%$ premixed ratios respectively, by using diesel fuel as shown in Figure 8A and using 30\% blend of waste cooked oil biodiesel with diesel fuel at Figure 8B. It is observed from the two graphs that the (NOx) emissions increase with increasing the engine load and its maximum value at the maximum load at each case of combustion, It is observed also that at any engine load the (NOx) emissions have the high percentages at the conventional combustion compared with the (PPCCI) combustion at 20\%, 25\% and 30\% premixed ratio which have low (NOx) emissions due to the reduction in the temperature of the combustion with increasing the premixed ratio at the (PPCCI) combustion. By comparison between the two graphs it is observed that the (NOx) emissions by using $30 \%$ blend of waste cooked oil biodiesel and diesel is smaller than (NOx) emissions using diesel fuel only at the same engine load, combustion and the same premixed ratio because of the low temperature combustion and the high Cetane number of the $30 \%$ blend of biodiesel and diesel. So by using (PPCCI) combustion with ascending premixed ratio with blends of biodiesel and diesel as a fuel the (NOx) emissions will reduce also it will reduce according to the engine load.

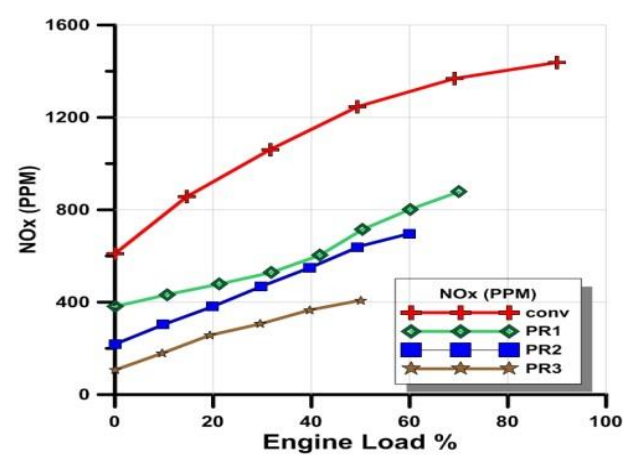

Figure 8A.Variation of (NOx) emissions with engine load using diesel fuel.

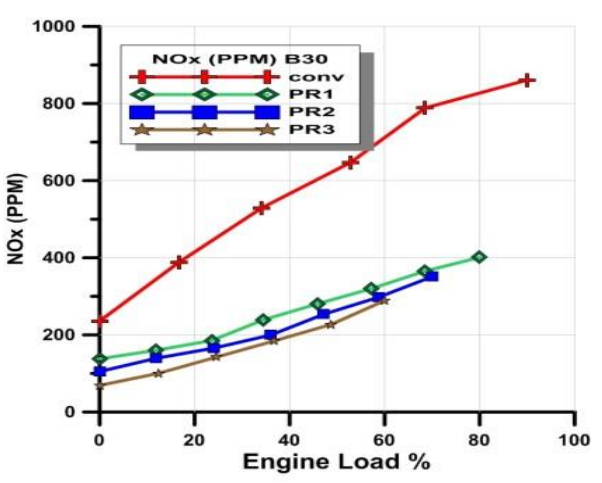

Figure 8B.Variation of (NOx) emissions with engine load using $30 \%$ blend of biodiesel and diesel.

\subsubsection{Unburned hydrocarbon}

Figures 9A and 9B show the unburned hydrocarbon (UHC) emissions with engine load for the conventional combustion and (PPCCI) combustion at $20 \%, 25 \%$ and $30 \%$ premixed ratios respectively, by using diesel fuel as shown in Figure 9A and using 30\% blend of waste cooked oil biodiesel with diesel fuel at Figure 9B. It is observed from the two graphs that the (UHC) emissions decrease with increasing the engine load and its minimum value at the maximum load at each case of combustion, It is observed also that at any engine load the (UHC) emissions have the high values at the conventional combustion compared with the (PPCCI) combustion at 20\%, 25\% and $30 \%$ premixed ratio which have (UHC) emissions due to the high degree of homogeneity for the mixture of air and fuel with increasing the premixed ratio at (PPCCI) combustion which make the combustion more completely than the conventional combustion. By comparison between the two graphs it is observed that the (UHC) emissions by using $30 \%$ blend of waste cooked oil biodiesel and diesel is smaller than the (UHC) emissions using diesel fuel only at the same engine load, combustion and the same premixed ratio because of more oxygen exists and the high cetane number of the $30 \%$ blend of biodiesel and diesel which improve the combustion. So by using (PPCCI) combustion with ascending premixed ratio with blends of biodiesel and diesel as a fuel the (UHC) emissions will reduce also it will reduce according to the engine load. 


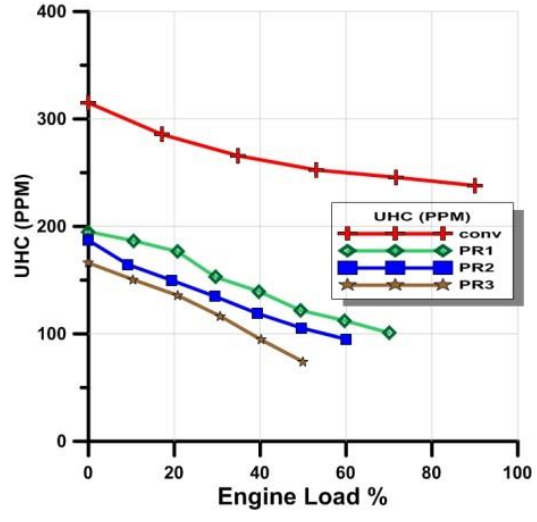

Figure 9A.Variation of unburned hydrocarbon emissions with engine load using diesel fuel.

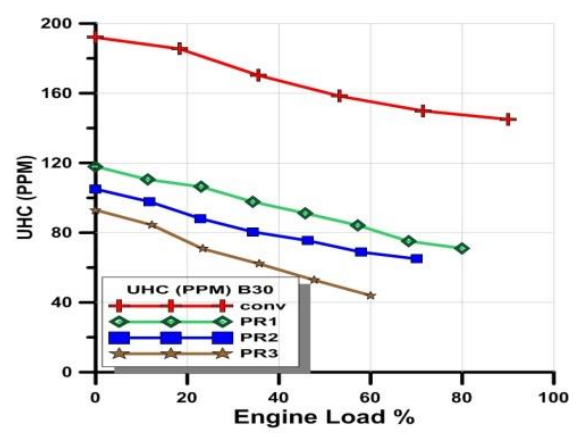

Figure 9B. Variation of unburned hydrocarbon emissions with engine load using $30 \%$ blend of biodiesel and diesel.

\subsubsection{Exhaust temperature}

\subsubsection{Smoke opacity}

Figures 10A and 10B show the smoke opacity with engine load for the conventional combustion and (PPCCI) combustion at 20\%, 25\% and 30\% premixed ratios respectively by using smoke analyzer (HPC 500) which inspect visually, by using diesel fuel as shown in Figure 10A and using $30 \%$ blend of waste cooked oil biodiesel with diesel fuel at Figure 10B. It is observed from the two graphs that the smoke opacity increase with increasing the engine load, It is observed also that at any engine load the smoke opacity have the high values at the conventional combustion compared with the (PPCCI) combustion at 20\%, 25\% and $30 \%$ premixed ratio which have lower smoke opacity emission percentages due to the high degree of homogeneity for the mixture of air and fuel with increasing the premixed ratio at (PPCCI) combustion which increase the ignition delay period and low carbon particles. By comparison between the two graphs it is observed the smoke opacity emission percentages by using $30 \%$ blend of waste cooked oil biodiesel and diesel is smaller than the smoke opacity emission using diesel fuel only at the same engine load, combustion and the same premixed ratio because of the low temperature of the combustion and the good homogeneity of the mixture by using $30 \%$ blend of biodiesel and diesel. So by using (PPCCI) combustion with ascending premixed ratio by blends of biodiesel and diesel as a fuel the smoke opacity emission will reduce compared to the smoke opacity emission by the conventional combustion using diesel fuel only.

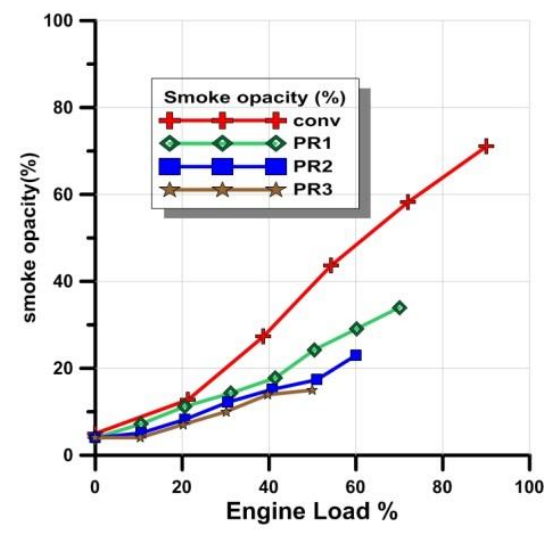

Figure 10A.Variation of the smoke opacity with engine load using diesel fuel.

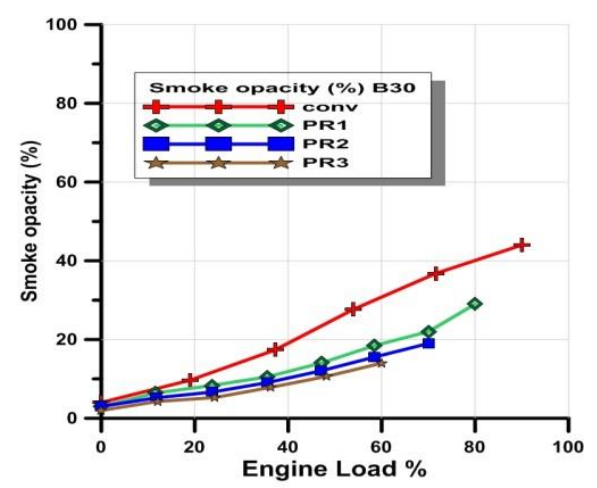

Figure 10B.Variation of the smoke opacity with engine load using $30 \%$ blend of biodiesel and diesel. 


\section{Conclusion}

The results of the research show the importance of the of the partially premixed charge compression ignition (PPCCI) engine fuelled with diesel only or blends of biodiesel and diesel on the performance and emission characteristics and the conclusion summarized that.

- The partially premixed charge compression ignition (PPCCI) combustion was difficult at high load due to the occurrence of knocking and also maintaining the premixed ratio was difficult to control.

- The brake thermal efficiency is high by using $20 \%, 25 \%$ and $30 \%$ premixed ratio at (PPCCI) combustion by using 30\% blend of biodiesel and diesel fuel compared with the conventional combustion with diesel fuel only.

\section{References}

[1] Gowthaman S, a review on methods of homogenous charge preparation for HCCI mode engine. international Journal of mechanical engineering and robotics research, 2015. 4(2): p. 16.

[2] Stanglmaier, R.H. and C.E. Roberts, Homogeneous Charge Compression Ignition (HCCI): Benefits, Compromises, and Future Engine Applications, 1999, SAE International.

[3] Bendu, H. and S. Murugan, Homogeneous charge compression ignition (HCCI) combustion: Mixture preparation and control strategies in diesel engines. Renewable and Sustainable Energy Reviews, 2014. 38: p. 732-746.

[4] Yao, M., Z. Zheng, and H. Liu, Progress and recent trends in homogeneous charge compression ignition (HCCI) engines. Progress in Energy and Combustion Science, 2009. 35(5): p. 398-437.

[5] Lü, X.-c.C., Wei Hou, Yu-chun Huang, Zhen, Study on the Ignition, Combustion and Emissions of HCCI Combustion Engines Fueled With Primary Reference Fuels, 2005, SAE International.

[6] Ganesh, D. and G. Nagarajan, Homogeneous charge compression ignition (HCCI)
- The brake specific fuel consumption is lower with $20 \%, 25 \%$ and $30 \%$ premixed ratio at (PPCCI) combustion using 30\% blend of biodiesel and diesel fuel compared with the conventional combustion with diesel fuel only.

- Reduction in the carbon monoxide, nitrogen oxides, unburned hydrocarbon, and smoke opacity emission at the (PPCCI) combustion using 30\% blend of biodiesel and diesel fuel compared with the conventional combustion with diesel fuel only.

\section{Acknowledgment}

The authors gratefully acknowledge the financial support officers from the office of the Tanta University Research Fund. This work was supported by the Tanta University Research Fund under the research grant (code: cod-tu; 03-15-02).

combustion of diesel fuel with external mixture formation. Energy, 2010. 35(1): p. 148-157.

[7] Tanaka, S.A., Ferran Keck, James C. Heywood, John B., Two-stage ignition in HCCI combustion and HCCI control by fuels and additives. Combustion and Flame, 2003. 132(1-2): p. 219-239.

[8] Xie, F.-X.L., Xiao-Ping Wang, Xin-Chao Su, Yan Hong, Wei, Research on using EGR and ignition timing to control load of a sparkignition engine fueled with methanol. Applied Thermal Engineering, 2013. 50(1): p. 10841091.

[9] Hussaini, S.Y., S. Lahane, and N.G. Patil, Analysis of Performance and Emission Characteristics of a Homogeneous Charge Compression Ignition (HCCI) Engine. Procedia Technology, 2016. 25(Supplement C): p. 854-861.

[10] Fang, T.L., Yuan-Chung Foong, Tien Mun Lee, Chia-fon, Biodiesel combustion in an optical HSDI diesel engine under low load premixed combustion conditions. Fuel, 2009. 88(11): p. 2154-2162.

[11] Singh, G., A.P. Singh, and A.K. Agarwal, Experimental investigations of combustion, performance and emission characterization of biodiesel fuelled HCCI engine using external 
mixture formation technique. Sustainable Energy Technologies and Assessments, 2014. 6(Supplement C): p. 116-128.

[12] Jiménez-Espadafor, F.J.T., Miguel Velez, José A. Carvajal, Elisa Becerra, José A., Experimental analysis of low temperature combustion mode with diesel and biodiesel fuels: A method for reducing NOx and soot emissions. Fuel Processing Technology, 2012. 103(Supplement C): p. 57-63.

[13] Singh, A.P. and A.K. Agarwal, An Experimental Investigation of Combustion, Emissions and Performance of a Diesel Fuelled HCCI Engine, 2012, The Automotive Research Association of India.

[14] Ying, W.L., He Jie, Zhou Longbao, Zhou, Study of HCCI-DI combustion and emissions in a DME engine. Fuel, 2009. 88(11): p. 2255-2261.

[15] Wu, H.-W.W., Ren-Hung Ou, Dung-Je Chen, Ying-Chuan Chen, Teng-yu, Reduction of smoke and nitrogen oxides of a partial HCCI engine using premixed gasoline and ethanol with air. Applied Energy, 2011. 88(11): p. 3882-3890.

[16] Kim, D.S. and C.S. Lee, Improved emission characteristics of HCCI engine by various premixed fuels and cooled EGR. Fuel, 2006. 85(5): p. 695-704.

[17] 1T.ILANGO, S.N., EFFECT OF COMPRESSION RATIO ON PARTIALLY PREMIXED CHARGE COMPRESSION IGNITION ENGINE FUELLED WITH METHANOL DIESEL BLENDS-AN EXPERIMENTAL INVESTIGATION. International Journal of Mechanical And Production Engineering, 2014. 2(8): p. 5.

[18] Saravanan, S., K. Pitchandi, and G. Suresh, An experimental study on premixed charge compression ignition-direct ignition engine fueled with ethanol and gasohol. Alexandria Engineering Journal, 2015. 54(4): p. 897-904.

[19] Sajjadi, B., A.A.A. Raman, and H. Arandiyan, A comprehensive review on properties of edible and non-edible vegetable oil-based biodiesel: Composition, specifications and prediction models. Renewable and Sustainable Energy Reviews, 2016. 63: p. 6292.

[20] Atabani, A.E.S., A. S. Badruddin, Irfan Anjum Mahlia, T. M. I. Masjuki, H. H. Mekhilef, S., A comprehensive review on biodiesel as an alternative energy resource and its characteristics. Renewable and
Sustainable Energy Reviews, 2012. 16(4): p. 2070-2093.

[21] Ito, T.S., Yusuke Kakuta, Yusuke Sugano, Motoyuki Hirano, Katsumi, Biodiesel production from waste animal fats using pyrolysis method. Fuel Processing Technology, 2012. 94(1): p. 47-52.

[22] Balat, M. and H. Balat, Progress in biodiesel processing. Applied Energy, 2010. 87(6): p. 1815-1835.

[23] Giakoumis, E.G.R., Constantine D. Dimaratos, Athanasios M. Rakopoulos, Dimitrios C., Exhaust emissions of diesel engines operating under transient conditions with biodiesel fuel blends. Progress in Energy and Combustion Science, 2012. 38(5): p. 691715.

[24] Sureshkumar, K., R. Velraj, and R. Ganesan, Performance and exhaust emission characteristics of a CI engine fueled with Pongamia pinnata methyl ester (PPME) and its blends with diesel. Renewable Energy, 2008. 33(10): p. 2294-2302.

[25] Chandra Sekhar, S.K., K. Vedaraman, N. Kabeel, A. E. Sathyamurthy, Ravishankar , Medhat Elkelawy , HagarAlm ElDin Bastawissi, Biodiesel production process optimization from Pithecellobium dulce seed oil: Performance, combustion, and emission analysis on compression ignition engine fuelled with diesel/biodiesel blends. Energy Conversion and Management, 2018. 161: p. 141-154.

[26] Mahmudul, H.M.H., F. Y. Mamat, R. Adam, A. Abdul Ishak, W. F. W. Alenezi, R., Production, characterization and performance of biodiesel as an alternative fuel in diesel engines - A review. Renewable and Sustainable Energy Reviews, 2017. 72: p. 497-509. 
A. Appendix

\section{A.1 Sample calculation}

-brake power

$(B P)=(v 1 \times i 1+v 2 \times i 2+v 3 \times i 3) \times \cos \varphi=$ $3.028 \mathrm{kw}$

-Mass fuel consumption

$m^{\circ}=m^{\circ} 1+m^{\circ} 2=0.6372 \frac{\mathrm{kg}}{\mathrm{hr}}$

$m^{\circ} 1=\frac{\rho f \times v f}{t} \quad m^{\circ} 2=\frac{(m 1+m 2)}{t}$

-Brake thermal efficiency

$\mu=B P /\left(m^{\circ} \times C V\right)=3600 /(S F C \times C V)$

$$
=41.6 \%
$$

-The air consumption measured by using air box with orifices and nozzles using

$\left(m^{\circ}\right)$ air $=\rho a \times v^{\circ}=C d \times A \times \sqrt{2 \rho a \Delta p}$

$\Delta p=\rho w \times g \times L \times \sin \theta$

\section{A.2 Uncertainty analysis}

Calculation of uncertainty in brake power

$\frac{\Delta B P}{B P}=\sqrt{3\left\{\left(\frac{\Delta v}{v}\right)^{2}+\left(\frac{\Delta i}{i}\right)^{2}\right\}}$

Calculation of uncertainty in mass fuel consumption

$\Delta m^{\circ} / m^{\circ}=\sqrt{ }\left\{\left(\frac{\Delta v f}{v f}\right)^{2}+\left(\frac{\Delta \mathrm{t}}{\mathrm{t}}\right)^{2}\right\}$

Calculation of uncertainty in brake thermal efficiency

$\Delta B T E / B T E=\sqrt{ }\left\{\left(\frac{\Delta B P}{B P}\right)^{2}+\left(\frac{\Delta \mathrm{m}^{\circ}}{\mathrm{m}^{\circ}}\right)^{2}\right\}$

\section{A.3 Sample calculation for uncertainty}

-Uncertainty in brake power

$=\sqrt{ } 3 \times\left\{[.1 / 155.9]^{2}+[.01 / 6.6]^{2}\right\}=0.0028 \mathrm{KW}$ $=0.28 \%$

-Uncertainty in mass fuel consumption

$=\sqrt{ }\left\{[.1 / 6]^{2}+[.01 / 50]^{2}\right\}=.0166 \mathrm{~kg} / \mathrm{hr} .=1.66 \%$

-Uncertainty in BTE

$=\sqrt{ }\left\{[.0028]^{2+}[.0166]^{2}\right\}=.0168=1.68 \%$ 